\title{
How do host sex and reproductive state affect host preference and feeding duration of ticks?
}

\author{
Nicholas B. Pollock • Larisa K. Vredevoe • \\ Emily N. Taylor
}

\begin{abstract}
Parasitism is one of the most notable forms of symbiosis in the biological world, with nearly all organisms hosting parasites. In many vertebrates, males have higher ectoparasite burdens than females, especially when testosterone concentrations are elevated. Furthermore, reproductive females may have higher ectoparasite burdens than non-reproductive females. It is possible that testosterone-stimulated behaviors in males and offspring investment by females incur energetic costs that inhibit immune function. If questing ticks can sense host sex or reproductive condition prior to attachment, they could potentially choose hosts with the poorest immune function, thereby leading to improved feeding success and decreased feeding duration. In this study, we examined the host-parasite relationship between western fence lizards (Sceloporus occidentalis) and the western black-legged tick (Ixodes pacificus) to test the following hypotheses: (1) ticks prefer male lizards to female lizards. (2) Ticks prefer male lizards with higher testosterone. (3) Ticks prefer reproductive female lizards to non-reproductive female lizards. (4) Ticks feed to repletion more rapidly (decreased feeding duration) on reproductive females and males with higher testosterone. In all three experiments, ticks failed to show a preference for one group over another as demonstrated by similar attachment rates between groups. This suggests that observed differences in ectoparasite loads in free-ranging lizards is due to some other factor than
\end{abstract}

host choice. However, tick feeding duration on female lizards was shorter when hosts were reproductive, suggesting that host reproductive condition alters tick feeding, possibly due to a decreased immune response. Interestingly, ticks fed more slowly on male lizards with elevated testosterone, suggesting that testosterone may actually improve immune function against ectoparasites.

\section{Introduction}

Interactions between hosts and their parasites greatly influence natural selection, with the evolution of improved host defenses leading to increased virulence and other pressures by the parasite (Lively 2010; Valens 1973). Some of the diverse pressures that parasites exert on their hosts include altered behavioral patterns (Bakker et al. 1997; Dunlap and Schall 1995; Klein 2003; Schall and Sarni 1987), decreased fitness (Baudoin 1975; Gooderham and Schulte-Hostedde 2011; Hamilton and Zuk 1982; de Lopé et al. 1998; Møller et al. 1999; Schall and Dearing 1987), and decreased immune function and overall health (Rechav et al. 1980; Salvador et al. 1996; Schall 1990). Numerous factors influence the degree of parasitism (i.e., parasite load and parasite feeding rate) in a given host individual, including abiotic factors like geographic locality and season, and biotic factors like host age, sex, health, hormone concentrations, and reproductive effort. In particular, host sex, hormone concentrations, and reproductive effort appear to be major, related determinants of parasite loads.

Male animals tend to have higher parasite loads than females (Poulin 1996; Zuk and McKean 1996) in diverse species from salamanders (Anthony et al. 1994), ball pythons (Aubret et al. 2005), and lizards (Klukowski and Nelson 2001; Salkeld and Schwarzkopf 2005; Schall and Marghoob 1995; 
Schall et al. 2000) to rodents (Moore and Wilson 2002; Morand et al. 2004), reindeer (Folstad et al. 1989), and birds (Zuk 1990; Tschirren et al. 2003). The explanation for this observation is not fully understood, but the androgenic hormone testosterone $(T)$ is believed to be a key factor. Lizards are particularly well suited for examining this relationship because they are heavily parasitized by ectoparasites, and the effects of $T$ can be easily studied both in the laboratory and in the field. Male lizards with experimentally elevated $T$ have higher parasite loads than control male lizards (Cox and JohnAlder 2007; Hughes and Randolph 2001; Klukowski and Nelson 2001; Olsson et al. 2000; Roberts et al. 2004; Saino et al. 1995; Salvador et al. 1996); however, the mechanism by which $T$ increases parasite loads is not known. In many lizard species, $T$ stimulates territorial behaviors and movements by males that could expose them to more parasites. Specifically, $T$ increases the frequency of territorial behaviors (Klukowski and Nelson 1998; Marler and Moore 1988, 1989; Moore 1986; Sinervo et al. 2000; Wingfield and Hahn 1994), home-range size (Cox et al. 2005; DeNardo and Sinervo 1994; John-Alder et al. 2009; Sinervo et al. 2000), and movement (Cox et al. 2005; John-Alder et al. 2009; Olsson et al. 2000; Sinervo et al. 2000). Additionally, $T$ may inhibit immune function (Belliure et al. 2004; Oppliger et al. 2004; Saad et al. 1990; Uller and Olsson 2003), which, in turn, could allow more parasites to infest, feed, and survive on males than on females. For example, Veiga et al. (1998) showed that when $T$ concentrations are artificially increased in male lizards (Psammodromus algirus), immune function decreases and ectoparasite load increases.

Related to circulating $T$ concentrations, reproductive effort of the host may impact parasite loads. Reproductive effort is defined as the proportion of resources invested in reproduction (Ricklefs 1977; Tuomi et al. 1983; Vitt and Congdon 1978). In male lizards, peak reproductive effort occurs during the mating season when circulating $T$ concentrations are high (Brasfield et al. 2008; Goldberg 1974; Tokarz et al. 1998). Testosterone increases energy expenditure through longer daily activity periods and increases in frequency of territorial behavior. Marler and Moore (1989) demonstrated that $T$-implanted male mountain spiny lizards (Sceloporus jarrovi) made fewer foraging attempts, caught fewer prey, had lower gut content mass, and had less stored energy in the form of lipids. Also, increases in circulating $T$ led to increases in metabolic rate (Buchanan et al. 2001; Oppliger et al. 2004). Increased energy expenditure, as an indirect result of increased circulating $T$, may preclude sufficient allocation of resources for optimal immune function. This trade-off could lead to increased parasite burdens on males with high $T$ concentrations. In females of oviparous species, peak reproductive effort occurs during vitellogenesis (French et al. 2007a; Tinkle 1969; Vitt et al. 1978) during which vitellogenin production diverts energy to yolk production. This process is energetically costly and can negatively impact immune function (Cichon et al. 2001; Nordling et al. 1998; Norris et al. 1994). For example, immune activity of female tree lizards (Urosaurus ornatus) is suppressed during vitellogenesis but only under conditions in which lizards are food-limited (French and Moore 2008; French et al. 2007a, b, c). Immunosuppression caused by increased reproductive effort may result in increased parasite loads, as observed in bats (Christe et al. 2000), birds (Nordling et al. 1998), and lizards (Sorci et al. 1996).

If variables such as sex, hormone concentrations, and reproductive effort affect tick feeding success, can ticks detect these conditions in order to choose the most appropriate hosts? It is well established that ticks utilize chemical, visual, and tactile cues to detect the presence of a host and to differentiate among host species (Wallade and Rice 1982). For example, ticks can detect particular chemicals isolated from a host's skin or hair (Dukes and Rodriguez 1976; Godfrey et al. 2011), and certain species of juvenile ticks clearly show interspecific host preferences among mammal, lizard, and bird hosts (Slowik and Lane 2009). However, few studies have examined whether ectoparasites can actually detect intraspecific host differences in condition and utilize this information to make choices prior to attachment.

The purpose of this study was to determine if larval western black-legged ticks (Ixodes pacificus) exhibit a preference for western fence lizards (Sceloporus occidentalis) with differing physiological conditions that could mediate tick feeding success. This species of lizard is often heavily parasitized by larval and nymphal stages of I. pacificus (Eisen et al. 2004), and male lizards have higher tick loads than females (Eisen and Eisen 1999; Eisen et al. 2001; Lumbad et al. 2011; Schall et al. 2000). We first tested the hypothesis that ticks prefer male lizards over female lizards; if this is true, then more larval ticks should attach and successfully feed on male than on female lizards in the laboratory. The second experiment tested the hypothesis that ticks prefer male lizards with high $T$ concentrations (representative of the mating season) over male lizards with low $T$ concentrations; if this is true, then a greater number of ticks should attach and successfully feed on males with elevated $T$ than on control males. The final experiment tested the hypothesis that ticks prefer reproductive (vitellogenic) female lizards over non-reproductive female lizards; if this is true, then a greater number of ticks should attach and successfully feed on reproductive female lizards than on nonreproductive females.

In addition to examining host choice, we calculated tick feeding duration. An intense host immune response can result in reduced tick feeding success in the form of reduced blood meal volume, prolonged feeding duration, and/or death of engorging ticks (reviewed in Wikel 1996; Wikel and Bergmann 1997; Willadsen and Jongejan 1999). We therefore used feeding duration as an indirect measure of host immune function. If increased reproductive effort inhibits immune function, 
especially in males, then feeding duration should be shorter on males than on females, on $T$-treated males than on control males, and on reproductive females than on non-reproductive females.

\section{Methods}

Study animals

Adult S. occidentalis were collected by hand-held noose from the Chimineas Ranch unit of the Carrizo Plain Ecological Reserve in San Luis Obispo Co., California, an area characterized by semi-arid grassland with scattered oak trees and numerous rock outcrops. In contrast to nearby coastal regions (Lumbad et al. 2011), I. pacificus very rarely infests $S$. occidentalis at Chimineas, likely because this habitat does not provide adequate humidity for I. pacificus development. Lizards were transported back to the California Polytechnic State University, San Luis Obispo in cloth bags, where snoutvent length (SVL, $\pm 0.5 \mathrm{~cm}$ ) and body mass $(\mathrm{g}, \pm 0.5 \mathrm{~g}$ ) were measured.

Laboratory populations of larval I. pacificus were generated for use in the study by feeding field-collected adults on bulls (Bos primigenius taurus) at the California Polytechnic State University beef unit. Adult ticks were collected by dragging fleece flags through trail-side grasses in a riparian habitat (Vredevoe et al. 1999) in Montaña de Oro State Park, California. Collected ticks were maintained at $23{ }^{\circ} \mathrm{C}$ and $100 \%$ humidity under 8:16 light/dark photoperiod in 20-ml plastic vials (Wheaton Science Products, Millville, NJ, U.S.A.) with mesh lids; vials contained a mixture of plaster of Paris with activated charcoal to prevent desiccation and retard mold growth. Replete female ticks were housed individually in vials as above until oviposition and larval emergence at 6-8 weeks. Larvae were held in the laboratory for approximately 4 weeks post-emergence before placement on lizards to ensure readiness for host feeding. For some trials, larval age was up to three months post-emergence.

\section{Host preference trials}

Study lizards for each of the three experiments (see below) were paired by SVL and body mass, and placed into $2.5 \mathrm{~L}$ beakers, each containing a microcentrifuge tube with 100 tick larvae. To permit host basking, beakers were placed close to a $60-\mathrm{W}$ incandescent lamp for approximately $12 \mathrm{~h}$. Fine mesh was secured around the top of the beaker with rubber bands to prevent tick escape from the beakers. Infestation trials spanned $48 \mathrm{~h}$ during which beakers were periodically misted with distilled water to prevent desiccation of the larvae. Lizards were then removed, the number of residual unattached ticks was recorded, and lizards were placed into individual $13 \times 8 \times$ $8(\mathrm{~cm})$ metal mesh cages elevated above tubs of water to collect ticks as they dropped off. Tubs were $30 \times 16 \times 8(\mathrm{~cm})$ and filled with $4 \mathrm{~cm}$ of water, such that any ticks dropping off the host lizards would fall into the tubs and float until they were retrieved daily by the investigators. The sides of the tubs were coated with Fluon (Bioquip, Rancho Dominguez, CA, USA) to prevent tick escape. Tubs were placed in environmental chambers $\left(27^{\circ} \mathrm{C}, 8: 16\right.$ light/dark). Water was offered ad libitum and two to three crickets were offered per day. Replete and unfed tick numbers were quantified daily as ticks dropped off into the water for approximately 3 weeks, until all ticks were collected. At the termination of the experiment the total number of unfed ticks, replete ticks, and feeding duration (average time to engorgement and drop off) were calculated for each lizard.

Experiment 1: effect of host sex on tick preference and feeding duration

Male-female host-preference experiments were performed at three different time periods during 2009: spring (20 April to 9 May, $n=13$ adult lizards of each sex), early summer (10 May to 4 June, $n=12$ ), and mid-summer (21 June to 13 July, $n=12$ ), chosen to examine lizards at times of varying reproductive condition and hormone concentrations. In this species, circulating $T$ concentrations are high in males in the spring and low in the summer (Taylor et al., unpublished data). Female lizards were deemed vitellogenic if follicles were detected by palpation. All spring and early summer females were nonvitellogenic, and all mid-summer females were vitellogenic. Male and female lizard pairs were not significantly different in SVL (spring, $T=0.24, P=0.814$; early summer, $T=0.31, P=$ 0.760 ; mid-summer, $T=1.81, P=0.089$ ) or body mass (spring, $T=-0.80, P=0.429$; early summer, $T=0.20, P=0.842$ ). However, male and female lizards paired together in mid-summer were significantly different in body mass with males being heavier $(T=3.52, P=0.002)$. Male and female lizards were paired together by SVL and body mass, and infested with tick larvae as above.

Experiment 2: effect of testosterone on tick preference and feeding duration

This study was performed during late summer (September 2009), when male lizards have low circulating $T$ concentrations (Taylor et al., unpublished data). Lizards were randomly assigned to one of two treatment groups, $T$-implanted $(n=14)$ or control $(n=14)$. The treatment groups did not significantly differ in SVL $(T=-0.23, P=0.821)$ or body mass $(T=0.60$, $P=0.554)$. Implants were made from $5 \mathrm{~mm}$ pieces of silastic diffusion tubing (Dow Corning, Clarkesville, TN, USA1.47-mm inner diameter, 1.96-mm outer diameter), capped and sealed with silicon caulking, and filled with either $3 \mathrm{~mm}$ 
of crystalline testosterone propionate (Sigma-Aldrich, St. Louis, MO, USA; T-implanted) or silicon caulking (control). Prior to implantation, lizards were placed on ice to undergo cold-induced surface anesthesia until they exhibited no footwithdrawal reflex. Implants were placed into the coelomic cavity via a small ventrolateral incision that was then closed with absorbable suture. Lizards were housed outdoors for a 14-day period (to allow recovery from surgery and the implants to take effect) in 2.4-m diameter snapset kiddie pools (Intex Recreation Corp., Long Beach, CA, USA) containing sand substrate, plants for shade, cinder blocks for basking, and water and food ad libitum. At the end of this treatment period, lizards were bled from the postorbital sinus with heparinized capillary tubes to determine $T$ concentration. Blood samples were centrifuged for $5 \mathrm{~min}$ at $10,000 \mathrm{rpm}$, and plasma was extracted and frozen at $-20^{\circ} \mathrm{C}$. Plasma samples were quantified by radioimmunoassay according to the methods of Lind et al. (2010). All samples were run in the same assay. Mean recovery was $81 \%$. The average intra-assay coefficient of variation was $7 \%$. $T$-implanted and control lizards were then paired together by SVL and body mass and infested with tick larvae as above.

Experiment 3: effect of vitellogenesis on tick preference and feeding duration

This study was performed during late summer (August 2009) when female lizards were not vitellogenic, confirmed by palpation. Adult female lizards were captured, brought to the laboratory, and randomly placed into one of two treatment groups, vitellogenic $(n=12)$ or non-vitellogenic $(n=12)$. The two groups were not significantly different in SVL $(T=0.21$, $P=0.836)$ or body mass $(T=0.88, P=0.393)$. Lizards were housed outdoors in kiddie pools as in Experiment 2, and those in the vitellogenic group were injected intracoelomically with $0.10 \mathrm{ml}$ of follicle-stimulating hormone (FSH, Sigma-Aldrich, St. Louis, MO, USA) dissolved in reptile ringers solution (0.05 mg FSH/0.1 ml reptile ringers solution) every other day for 24 days, until palpation indicated they were vitellogenic. Non-vitellogenic lizards were injected intracoelomically on the same schedule with an identical volume of reptile ringers solution. Vitellogenesis was confirmed in all treated lizards (and lack of vitellogenesis in control lizards) after the experiment by post-mortem dissection. At the end of the 24-day treatment period, female lizards were paired together by SVL and body mass, and infested with ticks as above.

\section{Statistical analyses}

Plasma $T$ concentrations of $T$-implanted and control lizards were compared with two-sample $t$ tests. Numbers of replete ticks for treatment groups (male versus female within each season, T-implanted versus control, and vitellogenic versus non-vitellogenic) were compared using repeated measures ANOVA. Numbers of unfed ticks for the treatment groups were compared using paired $t$ tests. To examine the effects of body size on numbers of replete ticks, we conducted analyses of covariance (ANCOVA) with log-transformed SVL as the covariate, comparing log-transformed replete tick loads between treatment groups (male versus female within each season, $T$-implanted versus control, and vitellogenic versus nonvitellogenic). The homogeneity of slopes assumption of all ANCOVAs was met. Tick feeding duration between treatment groups were compared using two-sample $t$ tests. For the male versus female host choice studies, a one-way ANOVA with Tukey pair-wise post-hoc comparisons assuming equal variances was performed to compare feeding duration among the three different time periods (spring, early summer, and midsummer) separately for male and female lizards. All $t$ tests were two-tailed and all $p$ values were considered significant at the $\alpha=0.05$ level. Statistical analyses were performed using SAS version 9.2 (Cary, NC, USA).

\section{Results}

Experiment 1: effect of host sex on tick preference and feeding duration

Average numbers of unfed ticks, replete ticks, and feeding durations for each study are shown in Table 1. There were no significant differences in replete tick loads on male versus female lizards: spring (mean replete ticks - males= $23.7 \pm 4.5$, females $=17.9 \pm 3.4 ; F=1.69, P=0.206$; Fig. 1a), early summer (mean replete ticks - males $=25.3 \pm 2.9$, females $=19.9 \pm 2.8 ; F=1.22, P=0.282$; Fig. $1 \mathrm{~b}$ ), and midsummer (mean replete ticks - males $=27.8 \pm 4.9$, females $=$ $23.7 \pm 4.6 ; F=0.00, P=0.975$; Fig. 1c). Furthermore, there were no significant differences in the numbers of unfed ticks that dropped off male versus female lizards - spring (mean unfed ticks - males $=4.6 \pm 0.7$, females $=4.69 \pm 1.1$; twotailed $T=0.06, P=0.952$ ), early summer (mean unfed ticks, males $=2.23 \pm 0.4$, females $=3.62 \pm 0.4$; two-tailed $T=1.85$, $P=0.089$ ), and mid-summer (mean unfed ticks-males $=$ $3.33 \pm 0.6$, females $=5.08 \pm 1.3$; two-tailed $T=1.22, P=$ 0.247). Snout-vent length did not significantly affect tick loads for any of the three time periods (spring $-F=2.92, P=$ 0.101 ; early summer $-F=0.71, P=0.409$; mid-summer$F=0.64, P=0.433$ ).

Tick feeding duration on male versus female lizards did not significantly differ during spring (mean durationmales $=12.8 \pm 0.5$ days, females $=13.0 \pm 0.4$ days; two-tailed $T=-0.54, P=0.600$ ) and early summer (mean duration-males $=12.9 \pm 0.3$ days, females $=12.7 \pm 0.4$ days; two-tailed $T=$ $0.34, P=0.744$ ) time periods. However, ticks fed significantly faster on female lizards than on male lizards during the mid- 
Table 1 Mean ( \pm 1 SEM) number of unfed and replete Ixodes pacificus larvae and their feeding duration on Sceloporus occidentalis lizard hosts

\begin{tabular}{lclll}
\hline Group & $\begin{array}{l}\text { Number } \\
\text { of lizards }\end{array}$ & $\begin{array}{l}\text { Unfed } \\
\text { ticks }\end{array}$ & $\begin{array}{l}\text { Replete } \\
\text { ticks }\end{array}$ & $\begin{array}{l}\text { Feeding } \\
\text { duration } \\
\text { (days) }\end{array}$ \\
\hline Field animals & & & & \\
Males & 13 & $4.6 \pm 0.7$ & $23.7 \pm 4.5$ & $12.8 \pm 0.5$ \\
Spring & 12 & $2.23 \pm 0.4$ & $25.3 \pm 2.9$ & $12.9 \pm 0.3$ \\
Early summer & 12 & $3.33 \pm 0.6$ & $27.8 \pm 4.9$ & $13.4 \pm 0.3$ \\
Mid-summer & & & & \\
Females & 13 & $4.69 \pm 1.1$ & $17.9 \pm 3.4$ & $13.0 \pm 0.4$ \\
Spring & 12 & $3.62 \pm 0.4$ & $19.9 \pm 2.8$ & $12.7 \pm 0.4$ \\
Early summer & 12 & $5.08 \pm 1.3$ & $23.7 \pm 4.6$ & $11.5 \pm 0.2$ \\
Mid-summer & & & & \\
Lab animals & & & & \\
Males & 14 & $3.36 \pm 0.6$ & $29.7 \pm 3.1$ & $13.8 \pm 0.3$ \\
$T$ treated & 14 & $3.00 \pm 0.5$ & $26.6 \pm 4.2$ & $13.2 \pm 0.3$ \\
Control & & & & \\
Females & 12 & $1.18 \pm 0.3$ & $32.8 \pm 4.0$ & $14.8 \pm 0.4$ \\
Vitellogenic & 12 & $2.36 \pm 0.5$ & $26.6 \pm 4.1$ & $13.8 \pm 0.3$ \\
Non-vitellogenic & 12 & & & \\
\hline
\end{tabular}

See text and figures for results of comparisons among groups

summer time period (mean duration-males $=13.4 \pm 0.3$ days, females $=11.5 \pm 0.2$ days; two-tailed $T=4.53, P=0.001$ ), when female lizards were vitellogenic. Accordingly, feeding duration on female lizards was significantly shorter in midsummer than in spring and early summer time periods $(F=$ 5.52, $P=0.008$; Fig. 2a; Table 1), but feeding duration on male lizards across the three time periods did not significantly differ from one another $(F=0.54, P=0.589$; Fig. $2 \mathrm{~b}$; Table 1$)$.

Experiment 2: effect of testosterone on tick preference and feeding duration

Testosterone implantation nearly doubled circulating concentrations of $T$ ( $T$-implanted males $=35.7 \pm 2.0 \mathrm{ng} / \mathrm{ml}$, control males $=21.1 \pm 2.8 \mathrm{ng} / \mathrm{ml}$; two-tailed $T=-4.25, P \leq 0.0001)$. The $T$ concentrations of $T$-implanted males were, however, within the range of concentrations observed in free-ranging males during the mating season in the spring (Taylor et al., unpublished). There were no significant differences in replete tick loads (mean replete ticks $-T$-implanted males $=29.7 \pm 3.1$, control males $=26.6 \pm 4.2 ; F=0.21, P=0.653$; Fig. 3) and numbers of unfed ticks (mean unfed ticks - $T$-implanted males $=3.36 \pm 0.6$, control males $=3.00 \pm 0.5$; two-tailed $T=0.49$, $P=0.630)$ on $T$-implanted versus control male lizards. Snoutvent length did not significantly affect replete tick loads $(F=$ $0.20, P=0.660$ ). Ticks fed significantly faster on control males than on $T$-implanted males (mean duration- $T$-implanted
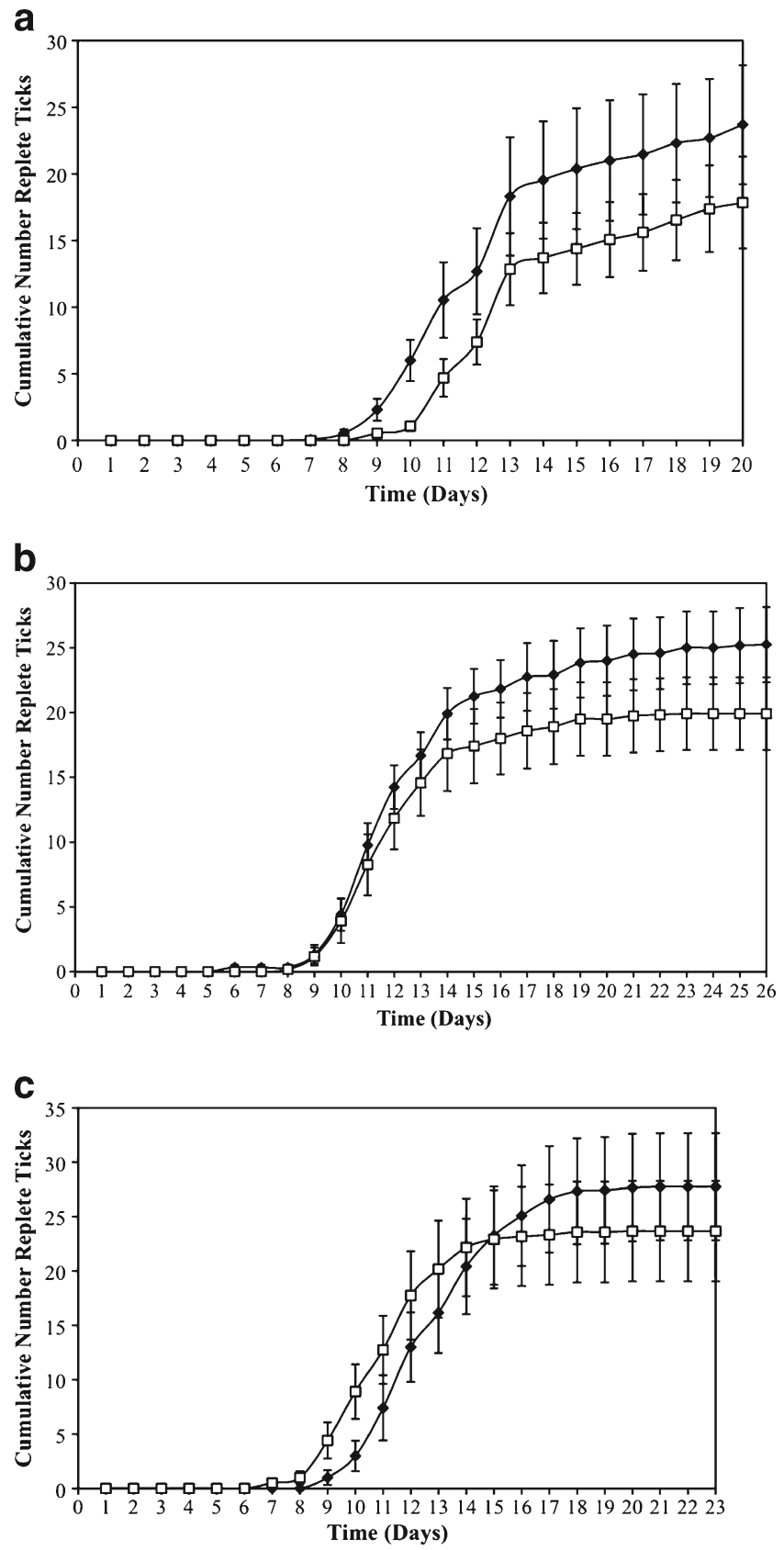

Fig. 1 Cumulative replete tick loads on male (filled diamonds) and female (open squares) lizards at three times of the year: spring (a), early summer (b), and mid-summer (c). Values are shown as means \pm 1 SEM

males $=13.8 \pm 0.3$ days, control males $=13.2 \pm 0.3$ days; twotailed $T=-2.30, P=0.038$ ).

Experiment 3: effect of vitellogenesis on tick preference and feeding duration

There were no significant differences in replete tick loads (mean replete ticks-vitellogenic $=32.8 \pm 4.0$, non-vitellogenic $=26.6 \pm$ $4.1 ; F=0.52, P=0.481$; Fig. 4) and numbers of unfed ticks 
a

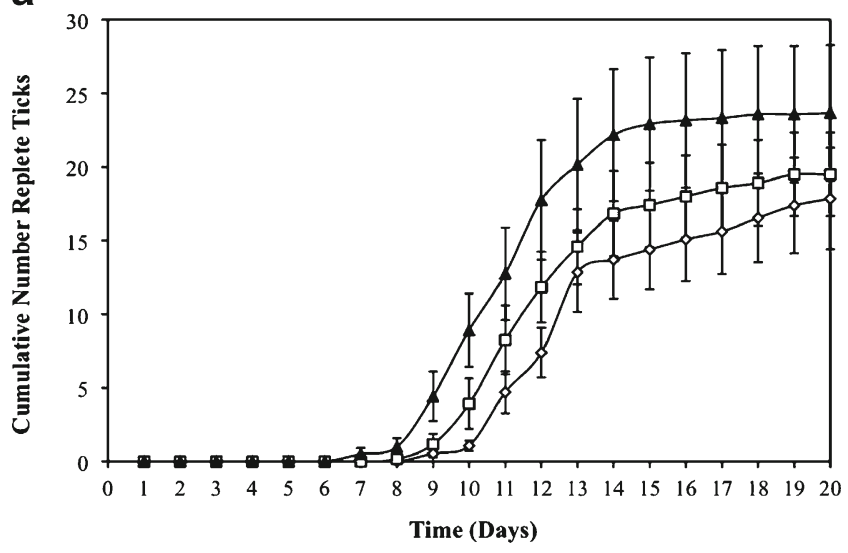

b

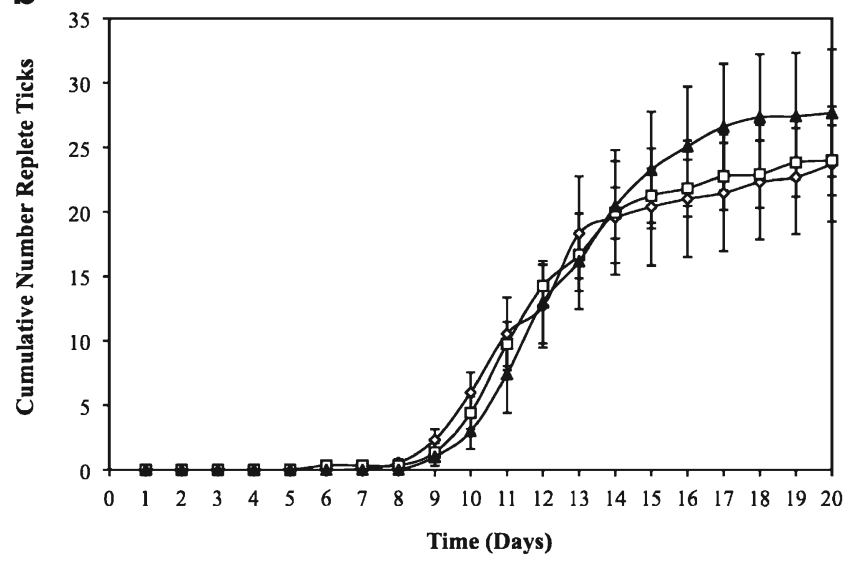

Fig. 2 Cumulative replete tick loads on male lizards (a) and female lizards (b) at three times of the year: spring (open diamonds), early summer (open squares), and mid-summer (filled triangles). Values are shown as means \pm 1 SEM

(mean unfed ticks - vitellogenic $=1.18 \pm 0.3$, non-vitellogenic $=$ $2.36 \pm 0.5$; two-tailed $T=1.72, P=0.115$ ) on vitellogenic versus non-vitellogenic female lizards. Snout-vent length did not significantly affect replete tick loads $(F=1.41, P=0.250)$. There was also no significant difference in feeding duration (mean duration: vitellogenic $=14.8 \pm 0.4$ days, non-vitellogenic $=13.8 \pm$ 0.3 days; two-tailed $T=-2.13, P=0.059$ ).

\section{Discussion}

While numerous studies have demonstrated that ticks can detect the presence of hosts and differentiate among host species (Dukes and Rodriguez 1976; James and Oliver 1990; Slowik and Lane 2009; Godfrey et al. 2011), ours is one of the first published studies examining whether ticks can detect and perhaps utilize host-based cues that reveal sex, hormonal concentrations, and reproductive effort prior to attachment. Carrick and Bullough (1940) showed that larval castor bean ticks (Ixodes ricinus) exhibited no preference

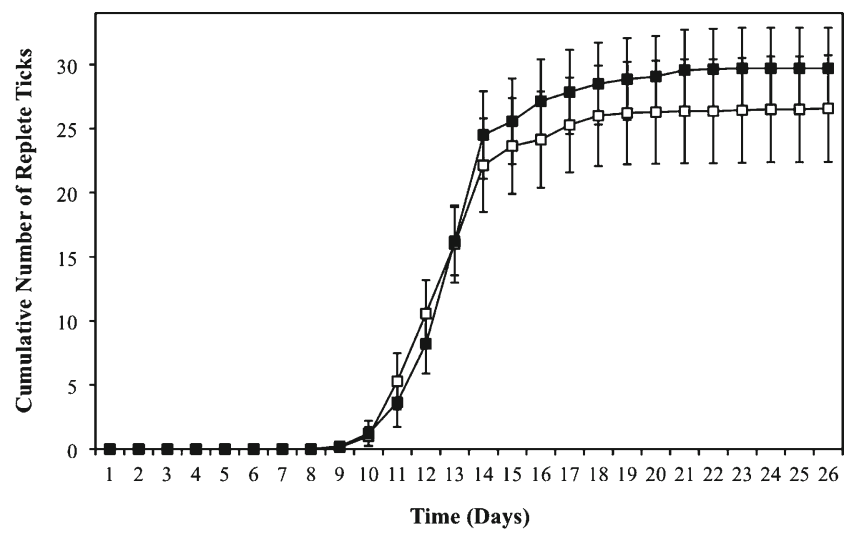

Fig. 3 Cumulative replete tick loads on testosterone-implanted (filled squares) and control (open squares) male lizards. Values are shown as means \pm 1 SEM

(rates of attachment and engorgement) when given a choice between reproductive and non-reproductive hedgehogs. In contrast, studies on bats showed that larger numbers of Spinturnix mites attached to individuals with better nutritional status (Christe et al. 2003) and pregnant as compared with non-reproductive female bats (Christe et al. 2000), suggesting that these mites may be able to sense host quality prior to attachment. In each of our experiments, however, similar numbers of ticks attached and fed to repletion on hosts in each of our experimental pairings, suggesting that I. pacificus larvae either do not detect host-based differences that we tested or do not exhibit a preference between $S$. occidentalis males and females, males with different $T$ concentrations, and reproductive versus non-reproductive females.

Our hypothesis that larval ticks prefer male lizards to female lizards was rejected. This experiment was repeated at three different times of the year to account for all combinations of reproductive condition: spring (males have high $T$ and females are not reproductive), early summer (males have low $T$ and females are not reproductive), and mid-summer (males have

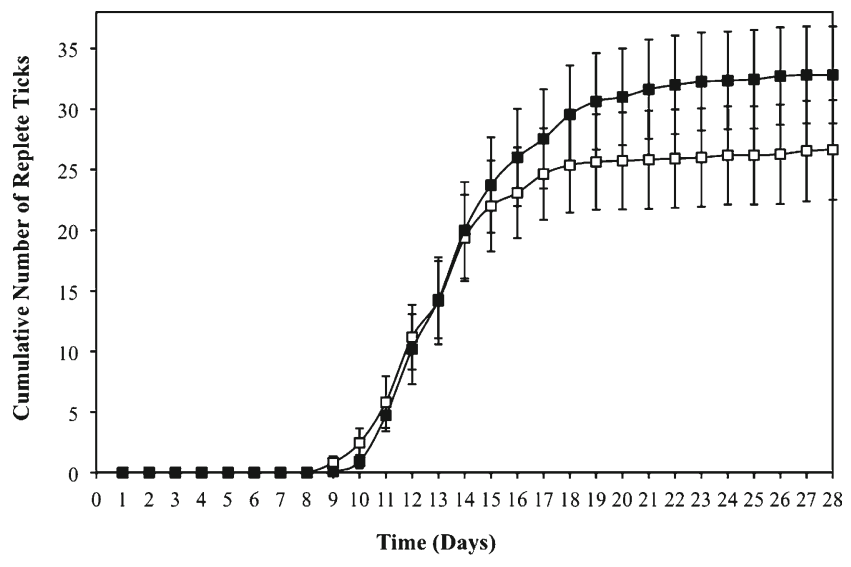

Fig. 4 Cumulative replete tick loads on vitellogenic (filled squares) and non-vitellogenic (open squares) female lizards. Values are shown as means \pm 1 SEM 
low $T$ and females are vitellogenic). Free-ranging male $S$. occidentalis have higher tick loads than female lizards (Eisen and Eisen 1999; Eisen et al. 2001; Lumbad et al. 2011; Schall et al. 2000); this sex difference must be due to a factor other than a preference for male hosts over females. Randolph (1998) postulated that for an ixodid tick species with a mean fecundity of 2,000 eggs, on average only 5, 10, and $20 \%$ of ticks will survive from eggs to larvae, larvae to nymphs, and nymphs to adults, respectively. Therefore, because of relatively low survival rates, it may be more beneficial for questing larval ticks to attach to any available host, otherwise they risk not encountering another host. Although questing ticks can clearly discern and show a preference for attachment and feeding on particular host species, they may be unable to detect intraspecific differences in host quality prior to attachment. Host seeking and attachment behavior may also change over time as a function of diminishing questing tick energetic resources and other factors. Factors that influence the rate at which ticks encounter hosts and that therefore influence mortality rates include temperature, day length, time of year, moisture, predation, and, in particular, the abundance of potential hosts (Daniel et al. 1976; Randolph 2004). It would be interesting to observe whether ticks exhibit differences in host preference under these varying conditions, for example in populations where host abundance is very high versus very low and in response to host species richness in a community.

There were no differences in the number of ticks that attached to males with experimentally elevated $T$ and control males, causing us to reject the hypothesis that ticks exhibit a preference for male lizards with higher circulating $T$ concentrations. Studies in free-ranging lizards in the field have documented increased ectoparasite loads in males with experimentally elevated $T$ (Cox and John-Alder 2007; Klukowski and Nelson 2001; Olsson et al. 2000; Saino et al. 1995; Salvador et al. 1996), including S. occidentalis (Pollock et al., in review). These results suggest an interesting role of $T$ in mediating ectoparasite loads. If ticks do not prefer males with high $T$, then $T$ must lead to increased tick loads in some other way. We suggest two possible hypotheses to explain this. Males generally have poorer immune function than females, often due to inhibitory effects of $T$ (Folstad and Karter 1992; Klein 2000; Mondal and Rai 1999, 2002; Tschirren et al. 2003; Zuk and McKean 1996). This could leave males more vulnerable to ectoparasitism by permitting more parasites to infest, feed, and survive. Alternatively, $T$ stimulates male territorial behaviors (Klukowski and Nelson 1998; Marler and Moore 1989; Moore 1986; Sinervo et al. 2000) and movement (Cox et al. 2005; John-Alder et al. 2009; Sinervo et al. 2000), thus potentially exposing male lizards to more questing parasites. This potential relationship between movement, activity, and tick load has been shown in chipmunks (Tamias sibiricus), with high tick loads being correlated with high spatial use and high activity level (Boyer et al. 2010). It is possible this same relationship is present in lizards. Therefore, $T$ appears to be an important factor mediating parasite load, although we found that ticks do not choose among hosts based on any cue altered by circulating $T$ concentrations.

Similar to the results from the other host preference experiments, there was no evidence of host preference when reproductive effort in female lizards was manipulated, leading us to reject the hypothesis that ticks prefer vitellogenic lizards over non-vitellogenic lizards. This again suggests that questing ixodid ticks may be unable to detect intraspecific differences in host physiological condition prior to attachment, or that reproductive condition alone does not negatively affect tick feeding success, and so there is no difference in host preference. We had expected more ticks to choose vitellogenic female lizards because vitellogenesis is an energetically costly process (French et al. 2007a; Tinkle 1969; Vitt et al. 1978), and under limited resources can lead to a reproductiveimmune trade-off (Cichon et al. 2001; Nordling et al. 1998; Norris et al. 1994) and increased parasite loads (Christe et al. 2000; Nordling et al. 1998; Sorci et al. 1996). However, in female tree lizards ( $U$. ornatus), immune activity was suppressed during vitellogenesis only under food-limited conditions (French and Moore 2008; French et al. 2007a, b, c). It is therefore possible that the ad libitum feeding regimen of our laboratory study prevented immune-reproductive trade-offs from occurring. It would be interesting to investigate in a future study whether ticks exhibit a preference for food-limited, vitellogenic female lizards.

When tick feeding duration was compared between male and female lizards, the only difference was observed during the mid-summer time period when males have low circulating $T$ and females are vitellogenic; that is, during the time when the difference in reproductive effort between the sexes is most pronounced. Ticks fed more quickly on females than males during this time period, and indeed ticks fed more quickly on female lizards in mid-summer than in the other time periods. Feeding duration was relatively constant for all lizards across all seasons, except in the vitellogenic mid-summer females, where the duration was decreased by an average of 1-2 days. One explanation for this difference is that the energetic demands of vitellogenesis in these field-collected lizards may have imparted decreased immune function (French et al. 2007a, b, c), permitting increased tick feeding rates. Upon attachment, a complex activation of immune attacks and defenses by both host and parasite is initiated. The saliva injected by ticks into the feeding lesion of the host skin is composed of an array of compounds that function to increase blood flow to the feeding tick, decrease clotting, and combat the host immune response (Brossard and Wikel 2004; Hovius et al. 2008; Ribeiro 1995; Schoeler and Wikel 2001). Hosts then mount a response against these compounds in the tick's saliva, thereby decreasing the efficiency of hematophagy by either prematurely shortening feeding duration, leading to 
early drop-off (partial repletion), or by killing the tick, often in situ (Brossard and Wikel 2004; Ribeiro 1989; Wikel et al. 1994). The host response involves integrin-stimulated blood coagulation, vasoconstrictors, and a complex immune response involving antigen-presenting cells, cytokines, $\mathrm{T}$ lymphocytes, natural killer cells, complement, and antibodies (Champagne and Valenzuela 1996). These components can disrupt blood meal acquisition, impair physiological processes, and kill the tick. Counteracting the host response are tick apyrases and disintegrin-like peptides that inhibit blood coagulation, vasodilators, and compounds that block the activation of the alternative complement pathway, inhibit the host antibody response, and suppress cytokine production (Champagne and Valenzuela 1996; Wikel et al. 1996). Inhibition of these host immune responses promotes a more favorable feeding environment for the tick. Consequently, initiating a robust immune response may increase tick feeding duration or in some cases prevent ticks from feeding to repletion. Vitellogenesis is an energetically expensive process (Bonnet et al. 1994; Braña et al. 1992), and if a female individual does not have appropriate resources to support both reproductive and immune systems during this time, then a trade-off may occur, leading to suppression of the immune response. This should be especially evident in free-ranging female lizards, as used in our study, which are often limited in food supply (French and Moore 2008; French et al. 2007a, b, c; Ruiz et al. 2011).

Ticks also fed significantly faster on the control lizards than on $T$-implanted lizards. This is contrary to our predictions, in that if $T$ diminishes the immune response, this should permit ectoparasites to feed more rapidly on hosts (Brossard and Wikel 2004; Ribeiro 1989; Wikel et al. 1994). Although the majority of studies have shown an inhibitory effect of $T$ on the immune system, several studies have shown the opposite effect (Tschirren et al. 2005). For example, in barn swallows, Saino et al. (1995) demonstrated that while $T$ was positively related to ectoparasite load, antibody levels, and number of eosinophils actually increased with experimentally elevated $T$. In another lizard species, $T$ appeared to enhance the immune response and reproductive capacity during periods of high food availability, but when resources were limited, $T$ inhibited the immune response (Ruiz et al. 2010). In our study, lizards were provided with ad libitum food for 2 weeks while implants took effect, raising the possibility that the combination of high food availability and increased $T$ concentrations possibly improved their immune response to ectoparasites. This intriguing possibility should certainly be studied further.

Interestingly, there was no significant difference in feeding duration between female lizards that were artificially induced into vitellogenesis and control lizards (Experiment 3). In Experiment 1, we observed that tick feeding duration was reduced in naturally vitellogenic females collected from the field site and immediately subjected to treatment. As demonstrated by French et al. (2007a, b, c) and Ruiz et al. (2011), the immune response of reproductive female lizards may only be impacted under conditions where there is not enough energy to support both immune and reproductive systems. The studies above found a decrease in immune function in reproductive lizards only when they were energy-limited; when food was available ad libitum, no differences were observed. All female lizards with artificiallyinduced vitellogenesis in our study were fed ad libitum for three weeks prior to infestation with ticks, which may have improved their nutritional status to the point where the energetic costs of vitellogenesis did not have negative impacts on their immune response to the ticks. To confirm this, as well as the hypothesis that energetic state modulates a $T$-induced alteration of immune function in males that then affects tick feeding duration, experimental manipulation of vitellogenesis and $T$ concentrations must be paired with controlled manipulation of food availability as in French et al. (2007a, b, c) and Ruiz et al. (2010, 2011).

The experiments described here are some of the first to explore the potential interplay between tick host preference in response to sex, hormonal concentrations, and reproductive effort in reptiles. The fact that no preference for hosts was observed in any of the host choice experiments in this study suggests that ticks lack the ability to detect the sex or physiological state of a potential host prior to attachment, or that these factors alone were not relevant to tick feeding success. This suggests that I. pacificus larvae do not select host lizards based on reproductive condition-related cues alone. Future studies should focus on determining the behavioral and physiological mechanisms that give rise to the observed effects of $T$ on parasitism in male hosts, and on the role of reproductive effort in mediating parasite load, immunosuppression, and fitness in female hosts.

Acknowledgments We would like to thank J Booza, J Frazier, A Gunterman, M Holding, C Lind, E McAdams, and A Sidhu for field and lab assistance, D Brewster for assistance in building lizard enclosures, A Lazanoff and M Hall for providing the bulls for tick feedings, $\mathrm{K}$ McGaughey for assistance with statistical analyses, and IT Moore for running hormone radioimmunoassays. This research was supported by the California Polytechnic State University Biological Sciences Department, a grant from the Chicago Herpetological Society, and a Gaige Award from the American Society of Ichthyologists and Herpetologists. Study procedures were approved by the California Polytechnic State University, San Luis Obispo, Institutional Animal Care and Use Committee (protocol \# 806) and the California Department of Fish and Game (California Scientific permit \# 801072-05).

\section{References}

Anthony CD, Mendelson JR III, Simons RR (1994) Differential parasitism by sex on Plethodontid salamanders and histological evidence for structural damage to the nasolabial groove. Am Midl Nat 132:302-307 
Aubret F, Bonnet X, Harris M, Maumelat S (2005) Sex differences in body size and ectoparasite load in the ball python, Python regius. J Herpetol 39:312-315. doi:10.1670/111-02N

Bakker TCM, Mazzi D, Zala S (1997) Parasite-induced changes in behavior and color make Gammarus pulex more prone to fish predation. Ecology 78:1098-1104. doi:10.1890/0012-9658(1997) 078[1098:PICIBA]2.0.CO;2

Baudoin M (1975) Host castration as a parasitic strategy. Evolution $29: 335-352$

Belliure J, Smith L, Sorci G (2004) Effect of testosterone on T cellmediated immunity in two species of Mediterranean lacertid lizards. J Exp Zool 301A:411-418. doi:10.1002/jez.a.20068

Bonnet X, Naulleau G, Mauget R (1994) The influence of body condition on $17-\beta$ estradiol levels in relation to vitellogenesis in female Vipera aspis. Gen Comp Endocr 93:424-437

Boyer N, Reale D, Marmet J, Pisanu B, Chapuis J (2010) Personality, space use and tick load in an introduced population of Siberian chipmunks Tamias sibiricus. J Anim Ecol 79:538-547

Braña F, González F, Barahona A (1992) Relationship between ovarian and fat body weights during vitellogenesis for three species of Lacertid lizards. J Herpetol 26:515-518

Brasfield SM, Talent LG, Janz DM (2008) Reproductive and thyroid hormone profiles in captive western fence lizards (Sceloporus occidentalis) after a period of brumation. Zoo Biol 27:36-48

Brossard M, Wikel SK (2004) Tick immunobiology. Parasitology 129: S161-S176. doi:10.1017/S0031182004004834

Buchanan KL, Evans MR, Goldsmith AR, Bryant DM, Rowe LV (2001) Testosterone influences basal metabolic rate in male house sparrows: a new cost of dominance signalling? Proc R Soc Lond B 268:1337-1344

Carrick R, Bullough WS (1940) The feeding of the tick, Ixodes ricinus $\mathrm{L}$., in relation to the reproductive condition of the host. Parasitology 32:313-317

Champagne DE, Valenzuela JG (1996) Pharmacology of haematophagous arthropod saliva. In: Wikel SK (ed) The immunology of host-ectoparasitic arthropod relationships. CAB International, Wallingford, pp 85-106

Christe P, Arlettaz R, Vogel P (2000) Variation in intensity of a parasitic mite (Spinturnix myoti) in relation to the reproductive cycle and immunocompetence of its bat host (Myotis myotis). Ecol Lett 3:207-212

Christe P, Giorgi MS, Vogel P, Arlettaz R (2003) Differential speciesspecific ectoparasitic mite intensities in two intimately coexisting sibling bat species: resource-mediated host attractiveness or parasite specialization? J Anim Ecol 72:866-872. doi:10.1046/ j.1365-2656.2003.00759.x

Cichon M, Dubiec A, Chadzinska M (2001) The effect of elevated reproductive effort on humoral immune function in collared flycatcher females. Acta Oecol 22:71-76

Cox RM, John-Alder HB (2007) Increased mite parasitism as a cost of testosterone in male striped plateau lizards Sceloporus virgatus. Funct Ecol 21:327-334

Cox RM, Skelly SL, John-Alder HB (2005) Testosterone inhibits growth in juvenile male eastern fence lizards (Sceloporus undulatus): implications for energy allocation and sexual size dimorphism. Physiol Biochem Zool 78:531-545

Daniel M, Cerny V, Dusbabek F, Honzakova E, Olejnicek J (1976) Influence of microclimate on the life cycle of the common tick Ixodes ricinus (L.) in thermophilic oak forest. Folia Parasitol 23:327-342

de Lopé F, Møller AP, de la Cruz C (1998) Parasitism, immune response, and reproductive success in the house martin Delichon urbica. Oecologia 114:188-193. doi:10.1007/s004420050435

DeNardo DF, Sinervo B (1994) Effects of steroid hormone interaction on activity and home-range size of male lizards. Horm Behav 28:273-287. doi:10.1006/hbeh.1994.1023
Dukes JC, Rodriguez JG (1976) A bioassay for host-seeking responses of tick nymphs (Ixodidae). J Kansas Entomol Soc 49:562-566

Dunlap D, Schall JJ (1995) Hormonal alterations and reproductive inhibition in male fence lizards (Sceloporus occidentalis) infected with the malarial parasite Plasmodium mexicanum. Physiol Zool 68:608-621

Eisen L, Eisen RJ (1999) Abundance of ticks (Acari: Ixodidae) infesting the western fence lizard, Sceloporus occidentalis, in relation to environmental factors. Exp Appl Acarol 23:731-740. doi:10.1023/A:1006212323760

Eisen RJ, Eisen L, Lane RS (2001) Prevalence and abundance of Ixodes pacificus immatures (Acari: Ixodidae) infesting western fence lizards (Sceloporus occidentalis) in northern California: temporal trends and environmental correlates. J Parasitol 87:1301-1307. doi:10.1645/0022-3395(2001)087[1301: PAAOIP]2.0.CO;2

Eisen L, Eisen RJ, Lane RS (2004) The roles of birds, lizards, and rodents as hosts for the western black-legged tick Ixodes pacificus. J Vector Ecol 29:295-308

Folstad I, Karter AJ (1992) Parasites, bright males, and the immunocompetence handicap. Amer Nat 139:603-622

Folstad I, Nilssen AC, Halvorsen O, Anderson J (1989) Why do male reindeer (Rangifer t. tarandus) have higher abundance of second and third instar larvae of Hypoderma tarandi than females? Oikos 55:87-92

French SS, Moore MC (2008) Immune function varies with reproductive stage and context in female and male tree lizards, Urosaurus ornatus. Gen Comp Endocr 155:148-156. doi:10.1016/j.ygcen. 207.04.007

French SS, DeNardo DF, Moore MC (2007a) Trade-offs between the reproductive and immune systems: facultative responses to resources or obligate responses to reproduction? Am Nat 170: 79-89

French SS, Johnston GIH, Moore MC (2007b) Immune activity suppresses reproduction in food-limited female tree lizards (Urosaurus ornatus). Funct Ecol 21:1115-1122. doi:10.1111/j.1365-2435. 2007.01311.x

French SS, McLemore R, Vernon B, Johnston GIH, Moore MC (2007c) Corticosterone modulation of reproductive and immune systems trade-offs in female tree lizards: long-term corticosterone manipulations via injectable gelling material. J Exp Biol 210:28592865. doi:10.1242/jeb.005348

Godfrey SS, Nelson NJ, Bull MC (2011) Microhabitat choice and hostseeking behaviour of the tuatara tick, Amblyomma sphenodonti (Acari: Ixodidae). N Z J Ecol 35:52-60

Goldberg SR (1974) Reproduction in mountain and lowland populations of the lizard Sceloporus occidentalis. Copeia 1974:176-182

Gooderham K, Schulte-Hostedde A (2011) Macroparasitism influences reproductive success in red squirrels (Tamiasciurus hudsonicus). Behav Ecol 22:1195-1200. doi:10.1093/beheco/arr112

Hamilton WD, Zuk M (1982) Heritable true fitness and bright birds: a role for parasites? Science 218:384-387. doi:10.1126/ science.7123238

Hovius JWR, Levi M, Fikrig E (2008) Salivating for knowledge: potential pharmacological agents in tick saliva. PLOS Med 5:0202-0208. doi:10.1371/journal.pmed.0050043

Hughes VL, Randolph SE (2001) Testosterone increases the transmission potential of tick-borne parasites. Parasitology 123:365-371. doi:10.1017'S0031182001008599

James AM, Oliver JH Jr (1990) Feeding and host preference of immature Ixodes dammini, I. scapularis, and I. pacificus (Acari: Ixodidae). J Med Entomol 27:324-330

John-Alder HB, Cox RM, Haenel GJ, Smith LC (2009) Hormones, performance, and fitness: natural history and endocrine experiments on a lizard (Sceloporus undulatus). Integr Comp Biol 49:393-407 
Klein SL (2000) The effects of hormones on sex differences in infection: from genes to behavior. Neurosci Biobehav R 24:627-638. doi:10.1016/S0149-7634(00)00027-0

Klein SL (2003) Parasite manipulation of the proximate mechanisms that mediate social behavior in vertebrates. Physiol Behav 79:441-449. doi:10.1016/S0031-9384(03)00163-X

Klukowski M, Nelson CE (1998) The challenge hypothesis and seasonal changes in aggression and steroids in male northern fence lizards (Sceloporus undulatus hyacinthinus). Horm Behav 33:197204. doi:10.1006/hbeh.1998.1449

Klukowski M, Nelson CE (2001) Ectoparasite intensities in freeranging northern fence lizards, Sceloporus undulatus hyacinthinus: effects of testosterone and sex. Behav Ecol Sociobiol 49: 289-295

Lind CM, Husak JF, Eikenaar C, Moore IT, Taylor EN (2010) The relationship between plasma steroid hormone concentrations and the reproductive cycle in the northern pacific rattlesnake, Crotalus oreganus. Gen Comp Endocrinol 166:590-599. doi:10.1016/ j.ygcen.2010.01.026

Lively CM (2010) Antagonistic coevolution and sex. Evo Edu Outreach 3:19-25. doi:10.1007/s12052-009-0196-2

Lumbad AS, Vredevoe LK, Taylor EN (2011) Season and host affect ectoparasite load in western fence lizards (Sceloporus occidentalis) on the California central coast. Southwest Nat 56:369-377

Marler CA, Moore MC (1988) Evolutionary costs of aggression revealed by testosterone manipulations in free-living male lizards. Behav Ecol Sociobiol 23:21-26. doi:10.1007/BF00303053

Marler CA, Moore MC (1989) Time and energy costs of aggression in testosterone- implanted free-living male mountain spiny lizards (Sceloporus jarrovi). Physiol Zool 62:1334-1350

Møller AP, Christie P, Lux E (1999) Parasitism, host immune function, and sexual selection. Q Rev Biol 74:3-20

Mondal S, Rai U (1999) Sexual dimorphism in phagocytic activity of wall lizard's splenic macrophages and its control by sex steroids. Gen Comp Endocr 116:291-298. doi:10.1006/gcen.1999.7370

Mondal S, Rai U (2002) In vitro effect of sex steroids on cytotoxic activity of splenic macrophages in wall lizard (Hemidactylus flaviviridis). Gen Comp Endocr 125:264-271. doi:10.1006/ gcen.2001.7744

Moore MC (1986) Elevated testosterone levels during non-breeding season territoriality in a fall-breeding lizard, Sceloporus jarrovi. J Comp Physiol A 158:159-163

Moore SL, Wilson K (2002) Parasites as a viability cost of sexual selection in natural populations of mammals. Science 297:20152018. doi:10.1126/science. 1074196

Morand S, De Bellocq JG, Stanko M, Miklisova D (2004) Is sexbiased ectoparasitism related to sexual size dimorphism in small mammals of Central Europe? Parasitology 129:505-510. doi:10.1017/S0031182004005840

Nordling D, Andersson M, Zohari S, Gustafsson L (1998) Reproductive effort reduces specific immune response and parasite resistance. Proc R Soc Lond B 265:1291-1298. doi:10.1098/ rspb.1998.0432

Norris K, Anwar M, Read AF (1994) Reproductive effort influences the prevalence of haematozoan parasites in great tits. J Anim Ecol 63:601-610

Olsson M, Wapstra E, Madsen T, Silverin B (2000) Testosterone, ticks, and travels: a test of the immunocompetence-handicap hypothesis in free ranging male sand lizards. Proc Roy Soc B 267:23392343. doi:10.1098/rspb.2000.1289

Oppliger A, Giorgi MS, Conelli GA, Nembrini M, John-Alder HB (2004) Effect of testosterone on immunocompetence, parasite intensity, and metabolism in the common wall lizard (Podarcis muralis). Can J Zool 82:1713-1719

Poulin R (1996) Sexual inequalities in helminth infections: a cost of being a male? Am Midl Nat 147:287-295
Randolph SE (1998) Ticks are not insects: consequences of contrasting vector biology for transmission potential. Parasitol Today 14:186192. doi:10.1016/S0169-4758(98)01224-1

Randolph SE (2004) Tick ecology: processes and patterns behind the epidemiological risk posed by ixodid ticks as vectors. Parasitology 129:S37-S65. doi:10.1017/S0031182004004925

Rechav Y, Kuhn HG, Knight MM (1980) The effects of the tick Amblyomma hebraeum (Acari: Ixodidae) on blood composition and weight of rabbits. J Med Entomol 17:555-560

Ribeiro JMC (1989) Role of saliva in tick/host interactions. Exp Appl Acarol 7:15-20. doi:10.1007/BF01200449

Ribeiro JMC (1995) How ticks make a living. Parasitol Today 11:9193

Ricklefs RE (1977) On the evolution of reproductive strategies in birds: reproductive effort. Am Nat 111:453-478

Roberts ML, Buchanan KL, Evans MR (2004) Testing the immunocompetence handicap hypothesis: a review of the evidence. Anim Behav 68:227-239. doi:10.1016/j.anbehav.2004.05.001

Ruiz M, French SS, Demas GE, Martins EP (2010) Food supplementation and testosterone interact to influence reproductive behavior and immune function in Sceloporus graciosus. Horm Behav 57:134139. doi:10.1016/j.yhbeh.2009.09.019

Ruiz M, Wang D, Reinke BA, Demas GE, Martins EP (2011) Trade-offs between reproductive coloration and innate immunity in a natural population of female sagebrush lizards, Sceloporus graciosus. Herpetol J 21:131-134

Saad AH, Khalek NA, El Ridi R (1990) Blood testosterone level: a season-dependent factor regulating immune reactivity in lizards. Immunobiology 180:184-194

Saino N, Møller AP AP, Bolzern AM (1995) Testosterone effects on the immune system and parasite infestations in the barn swallow (Hirundo rustica): an experimental test of the immunocompetence hypothesis. Behav Ecol 6:397-404. doi:10.1093/beheco/6.4.397

Salkeld DJ, Schwarzkopf L (2005) Epizootiology of blood parasites in an Australian lizard: a mark-recapture study of a natural population. Int J Parasitol 35:11-18. doi:10.1016/j.ijpara.2004.09.005

Salvador A, Veiga JP, Martin J, Lopez P, Abelenda M, Puerta M (1996) The cost of producing a sexual signal: testosterone increases the susceptibility of male lizards to ectoparasite infestation. Behav Ecol 7:145-150. doi:10.1093/beheco/7.2.145

Schall JJ (1990) Virulence of lizard malaria: the evolutionary ecology of an ancient parasite-host association. Parasitology 100:S35S52. doi:10.1017/S0031182000073005

Schall JJ, Dearing MD (1987) Malarial parasitism and male competition for mates in the western fence lizard, Sceloporus occidentalis. Oecologia 73:389-392. doi:10.1007/BF00385255

Schall JJ, Marghoob AB (1995) Prevalence of a malarial parasite over time and space: Plasmodium mexicanum in its vertebrate host, the western fence lizard Sceloporus occidentalis. J Anim Ecol 64:177-185

Schall JJ, Sarni GA (1987) Malarial parasitism and the behavior of the lizard, Sceloporus occidentalis. Copeia 1987:84-93

Schall JJ, Prendeville HR, Hanley KA (2000) Prevalence of the tick Ixodes pacificus, on western fence lizards, Sceloporus occidentalis: trends by gender, size, season, site, and mite infestation. J Herpetol 34:160-163

Schoeler GB, Wikel SK (2001) Modulation of host immunity by haematophagous arthropods. Ann Trop Med Parasitol 95:755771

Sinervo B, Miles DB, Frankino WA, Klukowski M, DeNardo DF (2000) Testosterone, endurance, and Darwinian fitness: natural and sexual selection on the physiological bases of alternative male behaviors in side-blotched lizards. Horm Behav 38:222-233. doi:10.1006/hbeh.2000.1622

Slowik TJ, Lane RS (2009) Feeding preferences of the immature stages of three western North American Ixodid ticks (Acari) for avian, 
reptilian, or rodent hosts. J Med Entomol 46:115-122. doi:10.1603/033.046.0115

Sorci G, Clobert J, Michalakis Y (1996) Cost of reproduction and cost of parasitism in the common lizard, Lacerta vivipara. Oikos $76: 121-130$

Tinkle DW (1969) The concept of reproductive effort and its relation to the evolution of life histories of lizards. Am Nat 103:501-516

Tokarz RR, McMann S, Seitz L, John-Alder H (1998) Plasma corticosterone and testosterone levels during the annual reproductive cycle of male brown anoles (Anolis sagrei). Physiol Zool 71:139-146

Tschirren B, Fitze PS, Richner H (2003) Sexual dimorphism in susceptibility to parasites and cell-mediated immunity in great tit nestlings. J Anim Ecol 72:839-845. doi:10.1046/j.13652656.2003.00755.x

Tschirren B, Saladin V, Fitze PS, Schwabl H, Richner H (2005) Maternal yolk testosterone does not modulate parasite susceptibility or immune function in great tit nestlings. J Anim Ecol 74:675-682. doi:10.1111/j.1365-2656.2005.00963.x

Tuomi J, Hakala T, Haukioja E (1983) Alternative concepts of reproductive effort, costs of reproduction, and selection in life-history evolution. Integr Comp Biol 23:25-34. doi:10.1093/icb/23.1.25

Uller T, Olsson M (2003) Prenatal exposure to testosterone increases ectoparasite susceptibility in the common lizard (Lacerta vivipara). Proc Roy Soc B 270:1867-1870. doi:10.1098/ rspb.2003.2451

Valen L (1973) A new evolutionary theory. Evol Theor 1:1-30

Veiga JP, Salvador A, Merino S, Puerta M (1998) Reproductive effort affects immune response and parasite infection in a lizard: a phenotypic manipulation using testosterone. Oikos 82:313-318

Vitt LJ, Congdon JD (1978) Body shape, reproductive effort, and relative clutch mass in lizards: resolution of a paradox. Am Nat 112:595-608
Vitt LJ, Van Loben Sels RC, Ohmart RD (1978) Lizard reproduction: annual variation and environmental correlates in the iguanid lizard Urosaurus graciosus. Herpetologica 34:241-253

Vredevoe LK, Richter PJ, Madigan JE, Kimsey RB (1999) Association of Ixodes pacificus (Acari: Ixodidae) with the spatial and temporal distribution of equine granulocytic ehrlichiosis in California. $\mathrm{J}$ Med Entomol 36:551-561

Wallade SM, Rice MJ (1982) The sensory basis of tick feeding behaviour. In: Obenchain FD, Galun R (eds) Physiology of ticks. Current themes in tropical science. Pergamon Press, Oxford, pp 71-118

Willadsen P, Jongejan F (1999) Immunology of the tick-host interaction and the control of ticks and tick-borne diseases. Parasitol Today 15:258-262

Wikel SK (1996) Host immunity to ticks. Annu Rev Entomol 41:1-22

Wikel SK, Bergmann D (1997) Tick-host immunology: significant advances and challenging opportunities. Parasitol Today 13:383389. doi:10.1016/S0169-4758(97)01126-5

Wikel SK, Ramachandra RN, Bergman DK (1994) Tick-induced modulation of the host immune response. Int J Parasitol 24:59-66. doi:10.1016/0020-7519(94)90059-0

Wikel SK, Ramachandra RN, Bergman DK (1996) Arthropod modulation of host immune responses. In: Wikel SK (ed) The immunology of host-ectoparasitic arthropod relationships. CAB International, Wallingford, pp 107-130

Wingfield JC, Hahn TP (1994) Testosterone and territorial behaviour in sedentary and migratory sparrows. Anim Behav 47:77-89. doi:10.1006/anbe.1994.1009

Zuk M (1990) Reproductive strategies and sex differences in disease susceptibility: an evolutionary viewpoint. Parasitol Today 6:231233. doi:10.1016/0169-4758(90)90202-F

Zuk M, McKean KA (1996) Sex differences in parasitic infections: patterns and processes. Int J Parasitol 26:1009-1024. doi:10.1016/ S0020-7519(96)80001-4 